\title{
Vitamin D Measurement, the Debates Continue, New Analytes Have Emerged, Developments Have Variable Outcomes
}

\author{
William D. Fraser ${ }^{1,2} \cdot$ Jonathan C. Y. Tang ${ }^{1} \cdot$ John J. Dutton ${ }^{1} \cdot$ Inez Schoenmakers $^{1}$
}

Received: 15 July 2019 / Accepted: 23 September 2019 / Published online: 18 November 2019

(c) The Author(s) 2019

\begin{abstract}
The demand for measurement of vitamin D metabolites for clinical diagnosis and to advance our understanding of the role of vitamin D in human health has significantly increased in the last decade. New developments in technologies employed have enabled the separation and quantification of additional metabolites and interferences. Also, developments of immunoassays have changed the landscape. Programmes and materials for assay standardisation, harmonisation and the expansion of the vitamin D external quality assurance scheme (DEQAS) with the provision of target values as measured by a reference measurement procedure have improved standardisation, quality assurance and comparability of measurements. In this article, we describe developments in the measurement of the commonly analysed vitamin D metabolites in clinical and research practice. We describe current analytical approaches, discuss differences between assays, their origin, and how these may be influenced by physiological and experimental conditions. The value of measuring metabolites beyond 25 hydroxyvitamin $\mathrm{D}$ $(25(\mathrm{OH}) \mathrm{D})$, the marker of vitamin D status, in routine clinical practice is not yet confirmed. Here we provide an overview of the value and application of the measurement of 1,25 dihydroxyvitamin D, 24,25 dihydroxyvitamin D and free 25OHD in the diagnosis of patients with abnormalities in vitamin $\mathrm{D}$ metabolism and for research purposes.
\end{abstract}

Keywords Vitamin D metabolites · Review $\cdot$ Assay $\cdot$ Immunoassay $\cdot$ Mass spectrometry $\cdot$ LC-MS/MS $\cdot 25$ Hydroxyvitamin $\mathrm{D}$

\section{Introduction}

Since the publication of our previous review, [1] there has been an ever increasing demand for the measurement of vitamin D metabolites. The technology employed to make measurements has changed and some additional metabolites have appeared that have useful but currently limited roles in clinical diagnosis but are improving our understanding of vitamin D metabolism. In this article, we will outline the developments in the measurement of several analytes and discuss the current approaches to the measurement of

William D. Fraser

W.Fraser@uea.ac.uk

1 Norwich Medical School, University of East Anglia, Norwich Research Park, Floor 2, Bob Champion Research and Education Building, James Watson Road, Norwich NR4 7UQ, UK

2 Departments of Diabetes, Endocrinology and Clinical Biochemistry, Norfolk and Norwich University Hospital NHS Foundation Trust, Colney Lane, Norwich, UK several major vitamin $\mathrm{D}$ metabolites. The possible role of Free 25 hydroxyvitamin D $(25(\mathrm{OH}) \mathrm{D})$ will be explored, and the importance of the programmes that are improving standardisation of measurements and the quality assurance of the measurements made will be discussed. Vitamin D metabolite measurements remain a challenge and as a recent international conference concluded despite great advances in our appreciation of vitamin D metabolism, measurements, biological actions on classical and non-classical tissues, and therapeutics, much more work remains to be done so that our knowledge base can become even more secure [2].

The value of measuring metabolites beyond $25(\mathrm{OH}) \mathrm{D}$, like 1,25 dihydroxyvitamin $\mathrm{D}\left(1,25(\mathrm{OH})_{2} \mathrm{D}\right)$, and 24,25 dihydroxyvitamin $\mathrm{D}\left(24,25(\mathrm{OH})_{2} \mathrm{D}\right)$ is not yet confirmed. In some complicated cases, these metabolites may provide the information needed for an accurate diagnosis. The problem is knowing when to measure, what to measure and how to measure. For $25(\mathrm{OH}) \mathrm{D}$, the most frequently used automated immunoassays do not meet the requirements of today's standards for certain patient groups and liquid chromatography-tandem mass spectrometry is the desired method of 
choice in these individuals. The less frequently measured $1,25(\mathrm{OH})_{2} \mathrm{D}$ metabolite enables us to identify a number of conditions, including $1 \alpha$-hydroxylase deficiency, hereditary vitamin D-resistant rickets and a number of granulomatous diseases or lymphoproliferative diseases accompanied by hypercalcaemia. $1,25(\mathrm{OH})_{2} \mathrm{D}$ measurement can help discriminate between the FGF23-mediated and non-FGF23mediated hypophosphatemic syndromes. The $24,25(\mathrm{OH})_{2} \mathrm{D}$ metabolite has proven its value in the diagnosis of idiopathic infantile hypercalcaemia (IIH) and has the potential of having value in identifying other diseases. For both metabolites, the understanding of the origin of differences between assays is limited and requires further attention. Appropriate measurement of vitamin D metabolism in the clinical laboratory hinges on comprehension of the value of the different metabolites, and the importance of the choice of method used to perform the measurements.

\section{Immunoassays for 25(OH)D}

Several developments in immunoassays have taken place, particularly in the automated assays. Manufacturers have tried to address the problems of specificity and sensitivity with several different approaches. Different methods of measurement have been tried, new reagents have been employed, and re-standardisation of assays has taken place. These approaches have had variable success. The performance of many assays is classified as "acceptable in the clinical setting" but in truth, some of the assays continue to demonstrate under-recovery of $25(\mathrm{OH}) \mathrm{D} 2$, cross-reactivity with vitamin D metabolites and variable bias in the vitamin D External Quality Assessment Scheme (DEQAS). Harmonisation remains an important goal for all assays but is yet to be universally achieved.

Abbott has introduced different generations of its fully automated assay and has standardised using the NIST Standard Reference Material (SRM) 2972 material. One evaluation reported $\mathrm{CVs} \leq 6.2 \%$ for all levels of the controls, with between-run uncertainties $\leq 0.36$ (expanded to $\leq 0.98$ with the inclusion of past generations of reagent) [3]. However, Annema et al. [4] reported a negative bias of $\leq 17.4 \%$ in the re-standardised Abbott Architect 25(OH)D assay compared with the LC-MS/MS method in samples from vitamin D insufficient $(<50 \mathrm{nmol} / \mathrm{L})$ subjects, and in those on vitamin D supplement. Further comparison with the Roche assay showed the Abbott assay underestimated 25(OH)D concentrations in insufficient subjects by up to $17.1 \%$ and overestimated in supplemented subjects.

The DEQAS scheme has reported the effects of endogenously added metabolites to samples evaluated by several assays [5]. The ability of the four commonly used automated immunoassays to cross-react with $25(\mathrm{OH}) \mathrm{D} 2$ was reported in an evaluation of vitamin D2 supplemented healthy adults [6]. Freeman et al. reported in a comparison study with ID-LC-MS/MS method, and all four immunoassays showed negative biases (Siemens ADVIA Centaur -7.1\%; DiaSorin LIAISON - 15.3\%; Roche ELECSYS $-8.4 \%$; Abbott ARCHITECT - 16.3\%) in samples containing $25(\mathrm{OH}) \mathrm{D} 2$ and $25(\mathrm{OH}) \mathrm{D} 3$, reflecting the varying degree of antibody cross-reactivity with the D2 metabolite. Wyness and Straseski evaluated six automated immunoassays (Beckman Coulter Access2 and UniCel DxI 800, Abbott ARCHITECT i2000SR, Siemens ADVIA Centaur XP, DiaSorin Liaison XL and Roche MODULAR E170) also concluded under-recovery of $25(\mathrm{OH}) \mathrm{D}$ in comparison to LC-MS/MS, with three of six immunoassays affected by the presence of $25(\mathrm{OH}) \mathrm{D} 2$. Only two of six immunoassays satisfied the recommended bias criteria of $<5 \%$ [7]. Dowling et al. had reported over-estimation of $25(\mathrm{OH}) \mathrm{D}$ measurements in the Roche assay due to the cross-reactivity of $24,25(\mathrm{OH})_{2} \mathrm{D}$ present in the samples [8]. Karvaly et al. had demonstrated the extent of the discrepancies between seven different methods on the interpretation of vitamin D status and found the DiaSorin Liaison had identified significantly more hypovitaminosis cases, whereas fewer cases were detected by IDSiSYS D assay [9]. Disparity can also occur in specific population groups; Hara et al. had reported falsely high $25(\mathrm{OH})$ $\mathrm{D}$ in serum samples from in infants and postpartum women produced by the Diasorin radioimmunoassay (RIA). A constant, disproportional positive bias was found in RIA results compared with LC-MS/MS [10].

A large number of immunoassay evaluations and comparisons exist in the literature. A small sample of these reports has been included in this review to demonstrate that there are significant differences in what authors feel is "acceptable" performance. While correlation coefficients and CVs are often deemed acceptable, it is clear that in certain clinical situations and when vitamin D2 is an exogenous supplement current immunoassays can give results that are inaccurate and could be misleading with over and underestimation of deficiency/sufficiency based on current definitions. It is important that users know the limitation of their assay and recognise when it is necessary to employ other methods of vitamin D measurement to obtain the clinically correct interpretation of a subject's vitamin D status.

\section{Immunoassays for $1,25(\mathrm{OH})_{2} \mathrm{D}$}

Developments in $1,25(\mathrm{OH})_{2} \mathrm{D}$ immunoassays have centred around the production of fully automated assays. The main commercial methods available have been produced by Diasorin and IDS. The DiaSorin LIAISON ${ }^{\circledR}$ XL 
chemiluminescent immunoassay utilises the ligand binding domain (LBD) of the vitamin D receptor for the capture of $1,25(\mathrm{OH})_{2} \mathrm{D}$ molecule, followed by a murine monoclonal antibody detection system that recognises the conformation change produced by the LBD- $1,25(\mathrm{OH})_{2} \mathrm{D}$ complex [11]. The method exploits the reaction conditions where binding differential of VDR highly favours $1,25(\mathrm{OH})_{2} \mathrm{D}$ over other forms of hydroxylated vitamin $\mathrm{D}$, and thus negates the need for immunoextraction. The Immunodiagnostic Systems (IDS) iSYS 1,25 VitDXp method involves an onboard immunopurification that has been modified from the IDS mini-immunocapsule extraction approach. The two-stage assay utilises an anti-1,25(OH $)_{2} \mathrm{D}$ antibody-coated magnetic particles to extract and enrich $1,25(\mathrm{OH})_{2} \mathrm{D}$ in the sample, followed by competitive binding against a $1,25(\mathrm{OH})_{2} \mathrm{D}$ labelled conjugate with a sheep anti-1,25(OH $)_{2} \mathrm{D}$ antibody for detection and amplification [12]. Comparison of the IDSiSYS assay and other immunoassays found results obtained with IDS-iSYS were lower than those obtained with IDSRIA by a mean of $20.4 \%$ with the following linear regression equation: $\mathrm{iSYS}=0.895$ RIA -8.1 . The analysis of 6 specimens from external quality assessment surveys showed means of inaccuracy bias of $-14.3 \%,-0.1 \%,-11.3 \%$ and $-8.9 \%$ in comparison with IDS-RIA ( $n=15$ laboratories), semi-automated iSYS $(n=9)$, Diasorin-RIA $(n=4)$ and all methods combined $(n=31)$, respectively [13]. In one study comparing the IDS-iSYS, Diasorin LIAISON assays and a LC-MS/MS assay there was a marked difference in performance reported. The DiaSorin assay performed better in terms of accuracy, sensitivity and imprecision compared to the IDS-iSYS assay. Total imprecision was 5.2\% or less for the DiaSorin assay but reached $20.1 \%$ for the IDS-iSYS assay. $1,25(\mathrm{OH})_{2} \mathrm{D}$ concentrations measured with the DiaSorin assay showed a strong correlation with $1,25(\mathrm{OH})_{2} \mathrm{D}$ levels measured by LC-MS/MS and a good agreement with method-specific means of DEQAS samples. By contrast, the IDS-iSYS test overestimated $1,25(\mathrm{OH})_{2} \mathrm{D}$ concentrations in human serum, particularly at higher concentrations [14].

Reference ranges have been established using immunoassays in healthy adults and patient groups $[15,16]$, but wide intervals reported cast concerns over assay specificity, given circulating concentration is tightly regulated. Higgins et al. [17] reported high disparity between the DiaSorin and LC-MS/MS methods in pooled neonates and infants samples with elevated $1,25(\mathrm{OH})_{2} \mathrm{D}$; a positive bias of up to $26.5 \%$ was observed in immunoassay results, and 3-epi$1,25(\mathrm{OH})_{2} \mathrm{D}$ was ruled out as a potential source of bias.

\section{5(OH)D by LC-MS/MS}

The marked increase in vitamin D workload, significant financial constraints and reduction, plus deskilling of the laboratory workforce, has seen many hospital laboratories swapping their "gold standard" LC-MS/MS methodologies, for more convenient high-throughput automated immunoassays despite the problems of immunoassays highlighted above. Increased regulatory requirements for validation, audit and traceability of "In-house" developed methods demanded by national and international regulatory authorities have helped drive this move.

Recently, in attempts to address the issues related to LC-MS/MS technology, several of the mass spectrometry vendors have invested significant resources in developing and validating their "total solution", to varying levels of success, complexity and completeness. Waters introduced their MassTrak Vitamin D Solution that is CE-marked in accordance with IVD Directive 98/79/EC per Annex III EC Declaration of Conformity, validated for use with the Waters ACQUITY UPLC ${ }^{\circledR}$ I-Class/Xevo TQD IVD System only and the sample preparation has been performed using the Tecan Freedom 100/4 EVO ${ }^{\circledR}$ Offline Automated Liquid Handling system. However, this has not been commercialised in the US market. The MassTrak Vitamin D Kit includes quality control reference materials and calibrations that are traceable to SRM 2972, aiding compliance with ISO 15189 guidelines, with a reported CV of $\leq 6.1 \%$ (range 4.1 to $6.1 \%$ ) for $25(\mathrm{OH}) \mathrm{D} 2$ and $\leq 6.8 \%$ (range 3.9 to $6.8 \%$ ) for $25(\mathrm{OH}) \mathrm{D} 3$, with a reportable range of $10 \mathrm{nmol} / \mathrm{L}$ to $375 \mathrm{nmol} / \mathrm{L}$ for both $25(\mathrm{OH}) \mathrm{D} 2$ and $25(\mathrm{OH}) \mathrm{D} 3$ [18]. Individual reagents and components are available. However, any change from the way the kit is validated constitutes off label use.

SCIEX followed a similar route, utilising their Class 1 Medical Device mass spectrometer-based IVD Topaz ${ }^{\mathrm{TM}}$ platform integrated with the Topaz Prep Station [19]. Coupled with the SCIEX Vitamin D 200M Assay Kit, this has been FDA approved (via the de novo pathway) and available in the US only. NIST traceable standardisation with reported measuring ranges of 2.0 to $165 \mathrm{ng} / \mathrm{mL}(5.0-412.5 \mathrm{nmol} / \mathrm{L})$ for $25(\mathrm{OH}) \mathrm{D} 2$ and 2.0 to $160 \mathrm{ng} / \mathrm{mL}(5-400 \mathrm{nmol} / \mathrm{L})$ for $25(\mathrm{OH}) \mathrm{D} 3$ with reproducibility $\mathrm{CV}$ of 4.2 to $6.1 \%$ for total 25(OH)D. Unlike the MassTrak solution, the Vitamin D 200M assay does not suffer from potential interference from 3-epi-25(OH)D2 and 3-epi-25(OH)D_3.

Both Waters and SCIEX offer "closed" assays that are run on "Open" access IVD platforms. The recently launched Thermo Scientific Cascadion ${ }^{\mathrm{TM}}$ SM Clinical Analyser is a fully automated "closed" random access CE-marked IVD device utilising LC-MS/MS, with online sample processing and TurboFlow technology interfaced to a tandem mass 
spectrometer via a duplex interface resulting in a throughput of 25 samples per hour. However, the system is currently only available for use outside of the US. Again, this has NIST aligned calibration and is free from potential epimer interferences with a reportable range of 5.6 to $423.8 \mathrm{nmol} / \mathrm{L}$ for $25(\mathrm{OH}) \mathrm{D} 2$ and 6.5 to $433.9 \mathrm{nmol} / \mathrm{L}$ for $25(\mathrm{OH}) \mathrm{D} 3$. Reported total precision for 25(OH)D2, 25(OH)D3, and total $25(\mathrm{OH}) \mathrm{D}$ are $\leq 6.1 \%, \leq 7.6 \%$, and $\leq 7.6 \%$, respectively [20].

It remains to be seen if such a radical approach to more LC-MS/MS assays, despite the inherent resource and financial support required to accomplish full validation and acceptance on a global scale will see a move away from "quick, easy and cheap" automated immunoassay systems. Interfacing to automated multidisciplinary tracking systems has to be an ultimate goal.

For those laboratories still determined to develop and validate their own "In-house" 25(OH)D LC-MS/MS and/ or metabolite profile methods, there are now NIST assigned ethanolic solutions and frozen human serum-based Standard Reference Materials (SRMs) available. Consequently, NIST/CDC aligned commercial calibration materials have also become available, as outlined in the following sections. However, there are still none available for $1,25(\mathrm{OH})_{2} \mathrm{D} 2$, $1,25(\mathrm{OH})_{2} \mathrm{D} 3,24,25(\mathrm{OH})_{2} \mathrm{D} 2$ or 3-epi-25(OH)D2 and it is a similar picture with the DEQAS scheme. These vitamin D2 metabolites are not currently at the vanguard of routine clinical practice and generally at low concentrations. As LC-MS/ MS assay specificity and sensitivity continue to improve, accurate quantitation of these minor metabolites may help in our understanding of the "unusual" clinical presentation.

Generally, LC-MS/MS quantification of vitamin D metabolites using triple quadrupole unit mass resolution instruments is the mainstay in clinical laboratories. The relatively recent introduction of bench-top high-resolution mass spectrometer instruments (Orbitrap MS and quadrupole time-of-flight MS) now offers the possibility of routine quantification of vitamin D metabolites using accurate mass, whilst also acquiring potentially important additional qualitative information from full scan acquisitions [21].

\section{Quality Assurance and Standardisation of 25(OH)D Assays}

Absolute and relative bias between different methodologies and within methods between different laboratories has been reported in the past [22]. In the last 10 years, much progress has been made to reduce bias and enable comparability between laboratories through the Vitamin D standardisation programme (VDSP) [22]. Recently, 15 clinical and research laboratories participated in an inter-laboratory comparison study coordinated by the VDSP; nearly all LC-MS/MS results achieved VDSP criteria $(\mathrm{CV} \leq 10 \%$ and mean bias $\leq 5 \%$ against NIST RMP/Ghent University), whereas only $50 \%$ of immunoassays met the criterion for a $\leq 10 \% \mathrm{CV}$ and only three of eight immunoassays achieved the $\leq 5 \%$ bias [23]. It is now widely accepted that a standardised measurement of $25(\mathrm{OH}) \mathrm{D}$ is a LC-MS/MS method that is aligned to NIST RMP, with quality assurance certified by DEQAS. In 2013, DEQAS had changed to an accuracy-based scheme with the NIST RMP. In 2017, NIST has released SRM 972a Vitamin D Metabolites in Frozen Human Serum as a replacement for SRM 972. The four levels of SRM 972a are composed of unmodified human serum and have been certified by three isotope-dilution mass spectrometry methods performed at NIST and at the CDC. The reference values include the 25(OH)D2, 25(OH)D3 and 3-epi-25(OH)D3 [24]. In addition, NIST issued a new high level SRM 2973 in frozen human serum, with assignment values of around $100 \mathrm{nmol} / \mathrm{L}$ to complement SRM972a [25]. From 2018, DEQAS target values were generated by the Nutritional Biomarkers Laboratory at the Centers for Disease Control and Prevention (CDC). The scheme has been further improved with the introduction of uncertainty values attached to each distribution sample [26]. Starting with the 2019 distribution cycle, the calculated total measurement uncertainty will allow DEQAS participants to determine their agreement and traceability to the NIST RMP.

Standardisation of $25(\mathrm{OH}) \mathrm{D}$ assays has begun to show an impact on the estimation of the prevalence of vitamin $D$ deficiency on a global scale. A VDSP study applied their standardised protocol to existing 25(OH)D values from 14 European population studies had found $13 \%$ of the 55,844 European individuals had serum $25(\mathrm{OH}) \mathrm{D}<30 \mathrm{nmol} / \mathrm{L}$ on average in the year, and $40.4 \%$ had $25(\mathrm{OH}) \mathrm{D}<50 \mathrm{nmol} / \mathrm{L}$. The high prevalence of vitamin $\mathrm{D}$ deficiency across the vast geographical footprint represents a major public health concern on an alarming scale [27].

\section{Free 25(OH)D}

The majority of vitamin D and its metabolites circulate in plasma bound to vitamin D binding protein (VDBP) $(\sim 85-90 \%)$ and to a lesser extent and with a lower binding affinity to albumin. Less than $1 \%$ circulates in its free form [28-30], i.e. for $25(\mathrm{OH}) \mathrm{D}$, free concentrations are in the picomolar range and for $1,25(\mathrm{OH})_{2} \mathrm{D}$ in the femtomolar range [29-33]. The free hormone theory states that only the free fraction can enter cells. This may however not fully apply to 25(OH)D since several organs express a megalinmediated internalisation mechanism for VDBP-bound metabolites. The free and total $25(\mathrm{OH}) \mathrm{D}$ concentrations in healthy people are strongly correlated [29, 30, 34, 35]. Specific physiological and pathological conditions are associated with alterations of plasma VDBP and the relationship 
between total and free $25(\mathrm{OH}) \mathrm{D}$, such as renal and liver disease and pregnancy $[31,36]$. The impact of these variations on tissue $25(\mathrm{OH}) \mathrm{D}$ availability is unclear. Compared to total $25(\mathrm{OH}) \mathrm{D}$, free $25(\mathrm{OH}) \mathrm{D}$ has been reported to be more strongly associated with PTH, bone mineral density (BMD) and various non-skeletal or calcaemic outcomes (e.g. risk of various types of cancer) in some but not all reports. This was recently reviewed by Bikle et al. [36]. There is also conflicting evidence regarding racial differences in the total to free $25(\mathrm{OH}) \mathrm{D}$ ratio. These findings may be confounded by methodological issues in one of the VDBP assays used, resulting in pronounced differences in VDBP concentrations between VDBP genotypes [30, 37].

There are several methods in use to obtain the value for free $25(\mathrm{OH}) \mathrm{D}$ and $1,25(\mathrm{OH})_{2} \mathrm{D}$ concentration: they are either calculated or directly measured, the results of which can vary $[29,30,38]$.

\section{Direct Measurement of Free 25(OH)D}

There are currently no assays for the direct measurement of the free fraction of any other metabolite than $25(\mathrm{OH}) \mathrm{D}$. The only assay for free $1,25(\mathrm{OH})_{2} \mathrm{D}$ was based on centrifugal ultra-filtration [33] and is now no longer in operation (personal communication Bikle).

Two assays for the direct measurement of free $25(\mathrm{OH})$ $D$ have been described. The first method was developed by Bikle and is based on centrifugal ultra-filtration [32]. The second is an immunoassay (Future Diagnostic, Wijchen, The Netherlands [39]). A third assay for the measurement of bioavailable 25(OH)D was described by Powe et al. [40], but no reports using this assay have been published. Currently, only the Future Diagnostic assay is commercially available and is widely used. The methodology and validation of this assay is briefly summarised below.

The assay free 25(OH)D enzyme-linked immunosorbent assay (ELISA) is a 2-step immunoassay using a 96-microtitre plate coated with a $25(\mathrm{OH}) \mathrm{D}$ antibody, specific for free $25(\mathrm{OH}) \mathrm{D}$. After addition of sample and incubation to allow binding of free $25(\mathrm{OH}) \mathrm{D}$, the plate is washed and biotinylated $25(\mathrm{OH}) \mathrm{D}$ is added. This will bind any unoccupied 25(OH)D antibody. After unbound biotinylated 25(OH)D is removed, the amount of antibody bound to biotinylated $25(\mathrm{OH}) \mathrm{D}$ is quantified by adding streptavidin peroxidase and subsequently $3,3^{\prime}, 5,5^{\prime}$-tetramethylbezidine chromogenic substrate. Bound streptavidin peroxidase is quantified spectrophotometrically with a plate reader at a wavelength of $450 \mathrm{~nm}$. This method has a measurement range of $2.4-35 \mathrm{pg} /$ $\mathrm{mL}$ and a limit of detection of $2.4 \mathrm{pg} / \mathrm{mL}$. Cross-reactivity with free $25(\mathrm{OH}) \mathrm{D} 2(77 \%)$ is lower than for 25(OH)D3 [39]. The accuracy of this assay was evaluated against a dialyses method (although this latter method itself was not validated, and there may be substantial issues with the use of dialysis for 25(OH)D [36]). However, also a comparison of results with the free 25(OH)D ELISA with the well-validated dialyses method as developed by Bikle provided similar results in samples from patients with conditions altering the $\%$ free to total 25(OH)D [36]. A proof of principle experiment was conducted by spiking samples with VDBP and albumin. This, as expected resulted in a significant reduction in the measured free $25(\mathrm{OH}) \mathrm{D}$ concentration in the free $25(\mathrm{OH}) \mathrm{D}$ [39]. To date, no quality assurance scheme, standard material or standardisation programme exists for free $25(\mathrm{OH}) \mathrm{D}$ assays. Generation of data on inter-laboratory comparability for the free $25(\mathrm{OH}) \mathrm{D}$ ELISA is underway.

\section{Calculated Free 25(OH)D and 1,25(OH $)_{2} \mathrm{D}$}

Algorithms for the calculation of the free concentrations are based on the concentrations of vitamin D metabolites and those of VDBP and albumin. Others calculate the bioavailable fraction, which equates to only the fraction not bound to VDBP and assumes the fraction bound to albumin and [41] other lipoproteins is bioavailable [40, 42]. A number of other authors have employed the ratio between VDBP and 25(OH)D [41, 43]. In most reports, the algorithm employed a constant binding affinity of VDBP and albumin for the vitamin D metabolite. These binding affinities were derived from Scatchard analyses [32,36]. Other algorithms incorporate a VDBP genotype-specific binding affinity [44], although the validity of VDBP-specific affinity constants has been debated [36, 45]. Also, the assumption that the binding affinity of VDBP and albumin remains constant under all physiological and pathological conditions may not be valid as discrepancies between directly measured and calculated free $25(\mathrm{OH}) \mathrm{D}$ were reported in pregnant women and liver disease [31].

Since the calculated free concentration is dependent on a composite of biochemical measurements, it relies on the accuracy of all of these measurements. Particular in the measurement of VDBP there is substantial variation between different methods. There are many different VDBP assays in use. Most commercially available assays are immune methods and thus dependent on antibody binding. Methods use either mono- or polyclonal antibodies. Polyclonal sera tend to include a variety of antibodies that react to a larger panel of epitopes of VDBP. In contrast to polyclonal antibodybased immune assays, assays using monoclonal antibodies typically result in different plasma VDBP concentrations across VDBP genotypes, dependent on the affinity of the antibody for the VDBP genotype. This is also not observed with quantification of VDBP by LC-MS/MS [30, 37, 46]. To date, no quality assurance scheme, standard material or standardisation programme exists for VDBP. This has led to 
substantial variation in the reported VDBP values and subsequently in calculated free $25(\mathrm{OH}) \mathrm{D}$ concentrations and to discrepant findings and conclusions [30,36]. These technical limitations have limited the research into the kinetics and role of the free fraction of vitamin D metabolites.

\section{$24,25(\mathrm{OH})_{2} \mathrm{D}$}

Measurement of serum $24,25(\mathrm{OH})_{2} \mathrm{D}$ was first reported in the late 1970s using competitive protein binding assays $[47,48]$ in animal and in vitro models to study the healing properties of $24,25(\mathrm{OH})_{2} \mathrm{D}$ on bone [49]. When HPLC methods with UV detection became the method of choice for $25(\mathrm{OH}) \mathrm{D}$, the improvement in assay sensitivity had remained insufficient to detect serum $24,25(\mathrm{OH})_{2} \mathrm{D}$, which circulates at concentrations around 10 -fold lower than $25(\mathrm{OH}) \mathrm{D}$. Shimizu et al. first reported a chemical derivatisation method for $24,25(\mathrm{OH})_{2} \mathrm{D}$ using a Cookson-type dienophilic agent. It reacts to the s-cis-diene moiety of vitamin D via the Diels-Alder reaction, forming a conjugated diene derivative for detection by HPLC with a fluorometric detector [50]. However, despite the improvement in assay sensitivity, studies in the 1980-1990s have found limited biological activity of $24,25(\mathrm{OH})_{2} \mathrm{D}$ in humans [51-53], and it was considered to be an inactive catabolic product of the vitamin D pathway [54]. The revival of interest in $24,25(\mathrm{OH})_{2} \mathrm{D}$ measurement was brought about after Genome-wide studies have pinpointed CYP24A1 as one of the major genetic determinants of variability in 25(OH)D [55]. Publications have shown CYP24A1 defects in children with IIH [56], in adults with nephrolithiasis and nephrocalcinosis [57], and in patients with chronic kidney disease [58] are associated with low serum $24,25(\mathrm{OH})_{2} \mathrm{D}$ concentration, and the genetic defect can be highlighted by an elevated $25(\mathrm{OH}) \mathrm{D}: 24,25(\mathrm{OH})_{2} \mathrm{D}$ vitamin $\mathrm{D}$ metabolite ratio (VMR). The introduction of LC-MS/MS in clinical laboratory has enabled stand-alone measurement of $24,25(\mathrm{OH})_{2} \mathrm{D}$, or in a profile analysis with $25(\mathrm{OH}) \mathrm{D}$ and $1,25(\mathrm{OH})_{2} \mathrm{D}$ to be performed in specialist laboratories. The use of a derivatisation agent has remained an essential step, especially when analysed using entry-level to mid-range LC-MS/MS systems. The most commonly described derivatisation agents for vitamin D metabolites in the literature (reviewed in [59]) are based on a substituted form of 1,2,4-triazoline-3,5-dione (TAD) at the 4-position (4-X-TAD). The Diels-Alder reaction is stable, robust, can be performed under ambient conditions and terminated by the addition of water. TAD derivatisation adds proton-affinitive oxygen and nitrogen molecules to the structure of vitamin $\mathrm{D}$, thus increasing ionisation potential. It also shifts the compound to a higher mass range, where background interference from low molecular weight species is relatively low. Non-derivatised methods require high-end LC-MS/MS instruments due to the poor ionisation efficiency of vitamin D metabolites, and often resort to the use of water loss precursor ions at low collision energy [60], which can be susceptible to interference by pseudo-molecular ions. It is important to note the different properties of the derivatisation agents; DMEQ-TAD (4-[2-(3,4-dihydro-6,7-dimethoxy-4-methyl-3-oxo-2-quinoxalinyl)ethyl]-TAD) forms two separate peaks for the $\mathrm{R}$ - and S-stereoisomers, and allows chromatographic separation of $23,25(\mathrm{OH})_{2} \mathrm{D}$ and $25,26(\mathrm{OH})_{2} \mathrm{D}$ [61]; DAP-TAD (4-4'-dimethylaminophenyl-TAD) [62] and Amplifex ${ }^{\mathrm{TM}}$ Diene [63] can achieve baseline separation of C3-epimers, whereas 2-nitrosopyridine can form distinct precursor and product ions for $24,25(\mathrm{OH})_{2} \mathrm{D}$ and $1,25(\mathrm{OH})_{2} \mathrm{D}$ [64] and thus increases assay selectivity. The majority of derivatisation agents are commercially available in ready to use powder or in the precursor forms. The improvement in sensitivity and specificity enable differential analysis of vitamin D metabolites, expanding the applicability in research and diagnostic investigations.

Measurement of serum $24,25(\mathrm{OH})_{2} \mathrm{D}$ is now available in specialist laboratories. Reference intervals between 1.1 and $13.5 \mathrm{nmol} / \mathrm{L}$ in a healthy population have been reported by the authors of this paper [65], and in others alike [66-68]. The serum concentration of $24,25(\mathrm{OH})_{2} \mathrm{D}$ is positively correlated with $25(\mathrm{OH}) \mathrm{D}$; evidence had shown $24,25(\mathrm{OH})_{2} \mathrm{D}$ to be an excellent surrogate predictor of vitamin D deficiency $[65,69,70]$. However, seasonal changes affect serum concentration in a manner similar to $25(\mathrm{OH}) \mathrm{D}$. Macdonald et al. reported a 2-fold increase in peak summer months (July-August in UK) in a longitudinal study [71]. The biological function of $24,25(\mathrm{OH})_{2} \mathrm{D}$ has yet to be elucidated; research studies have shown evidence in promoting fracture healing and protection against cartilage damage [72-75]. In clinical settings, $24,25(\mathrm{OH})_{2} \mathrm{D}$ measurement is best utilised when expressed in a ratio with $25(\mathrm{OH})$ $\mathrm{D}$, where $25(\mathrm{OH}) \mathrm{D}: 24,25(\mathrm{OH})_{2} \mathrm{D}$ VMR can indicate the vitamin $\mathrm{D}$ catabolic status of an individual and highlight 24-hydroxylase deficiency due to genetic abnormalities of CYP24A1. In a healthy population, $25(\mathrm{OH}) \mathrm{D}: 24,25(\mathrm{OH})_{2} \mathrm{D}$ VMR is between 7 and 23, and increases when vitamin D status becomes insufficient [65]. A ratio of $>80$ is associated with patients with heterozygous or biallelic mutations of CYP24A1 [67, 69]. Moderate elevation of $25(\mathrm{OH})$ $\mathrm{D}: 24,25(\mathrm{OH})_{2} \mathrm{D}$ VMR due to partial inactivity of CYP24A1 is associated with renal impairment $[58,76]$ and bone disorders [77]. 25(OH)D:24,25(OH) $)_{2} \mathrm{D}$ VMR has an advantage for being less susceptible to seasonal fluctuation [78], allowing interpretation using fixed reference intervals irrespective of the time of the year.

Measurement of $24,25(\mathrm{OH})_{2} \mathrm{D}$ and $25(\mathrm{OH})$ $\mathrm{D}: 24,25(\mathrm{OH})_{2} \mathrm{D}$ VMR has shown potential in optimising 
treatment response to vitamin D supplementation. The increased incidents of falls and fractures in the older population associated with the use of ultra-high doses of vitamin D administered annually or monthly $[79,80]$ suggests the correlation of risks vs benefit effects of vitamin D exhibit a U-shaped curve, rather than a J-shaped curve. Although higher doses of vitamin $\mathrm{D}$ supplement were more effective in reaching $25(\mathrm{OH}) \mathrm{D}$ concentration of $50 \mathrm{nmol} / \mathrm{L}$, high supplementation levels can be detrimental to the patients. A common strategy to correct vitamin D deficiency replacement is a loading dose followed by a daily maintenance dose, which can be optimised based on the characteristics of the patient, in combination with baseline profile of $25(\mathrm{OH}) \mathrm{D}$, $24,25(\mathrm{OH})_{2} \mathrm{D}$ measurements and VMR. Future research should aim to establish the appropriate dose and frequency of administration to achieve an increase in $25(\mathrm{OH}) \mathrm{D}$ while limiting the disproportional increase in $24,25(\mathrm{OH})_{2} \mathrm{D}$ concentrations. The use of VMR can provide insight that may begin to explain the lack of optimal response to increasing supplementation with vitamin D.

Efforts to standardise and improve inter-laboratory comparability of $24,25(\mathrm{OH})_{2} \mathrm{D}$ assays are in progress. NIST SRM972a and 2973 in frozen human serum are available with certified values for $24,25(\mathrm{OH})_{2} \mathrm{D} 3$ between 3.39 and $7.51 \mathrm{nmol} / \mathrm{L}$ [24]. DEQAS has introduced a pilot scheme since April 2015, but due to the small number of participants, albeit using LC-MS/MS methods, high inter-laboratory variability was observed, with CVs ranging between 19 and 29\% [81]. Wise et al. reported lower variability between five laboratories using isotopically labelled $24,25(\mathrm{OH})_{2} \mathrm{D} 3$ as internal standard [82]. The availability of referencetraceable, matrix-matched, multi-point calibration standards would improve method accuracy and commutability of results between laboratories.

\section{$1,25(\mathrm{OH})_{2} \mathrm{D}$ by LC-MS/MS}

LC-MS/MS methodology for $1,25(\mathrm{OH})_{2} \mathrm{D}$ has remained confined to laboratories with high-end instruments. To achieve adequate assay sensitivity without derivatisation requires extensive sample preparation to enrich sample concentration by either a manual immunoaffinity step [83,84] or online two-dimensional chromatography $[85,86]$. Chemical derivatisation with Cookson-type dienophilic agents is more commonly used. Of those methods described in this review, DAP-TAD was reported to produce the best ion potentials and assay sensitivity [87]. A LC-MS/MS assay has been developed that uses immunoextraction of $0.5 \mathrm{~mL}$ serum followed by Amplifex ${ }^{\mathrm{TM}}$ derivatisation of the dried eluent, with analysis using the SCIEX 6500+ instrument [88]. The limit of quantitation was $15 \mathrm{pmol} / \mathrm{L}$ and the method linear up to $600 \mathrm{pmol} / \mathrm{L}$. Repeatability ranged from $6.1 \%$ at $23 \mathrm{pmol} / \mathrm{L}$ to $2.5 \%$ at $172 \mathrm{pmol} / \mathrm{L}$ and imprecision was $15.6 \%$ at $26 \mathrm{pmol} / \mathrm{L}$ to $8.3 \%$ at $173 \mathrm{pmol} / \mathrm{L}$. The method was unaffected by icterus, haemolysis or lipaemia. Analysis of DEQAS samples demonstrated a negative bias compared with the all lab trimmed mean (average $-13.8 \%$ ) and the specific method group (average $-7.75 \%$ ). A negative bias was observed across the concentration range found in 78 patient samples in comparison to a commercial RIA (mean $-47.8 \%)$.

Long-term assay performance between all the immunoassay and LC-MS/MS methods is closely monitored by DEQAS. The lack of cross-assay reference standards has yet to be addressed. Since the introduction of the DiaSorin method on the Liaison XL platform, the use of manual radioisotopic immunoassays have been on a gradual decline. The shift has reduced inter-laboratory variability, but raised concern over the dominance of the DiaSorin method group amongst the participants in the DEQAS scheme, thereby strongly influencing the All Laboratory Trimmed Mean (ALTM), potentially masking method-specific bias.

$1,25(\mathrm{OH})_{2} \mathrm{D}$ measurements are mostly used in clinical settings or disease-focused patient studies. The use in healthy population-based or vitamin D supplementation studies is rare; serum concentration does not correlate with 25(OH)D. Despite being the most biologically active form of vitamin $\mathrm{D}$ metabolite, $1,25(\mathrm{OH})_{2} \mathrm{D}$ should not be used for the assessment of vitamin D status. Serum level is tightly regulated by the hydroxylation enzymes expressed by the actions of CYP27B1 and CYP24A1, and influenced by PTH and FGF23. The relationship of $1,25(\mathrm{OH})_{2} \mathrm{D}$ with other vitamin $\mathrm{D}$ metabolites is best described using VMR; the authors have reported in a large population of healthy army recruits, an exponential increase in $1,25(\mathrm{OH})_{2} \mathrm{D}: 24,25(\mathrm{OH})_{2} \mathrm{D}$ VMR when $25(\mathrm{OH}) \mathrm{D}$ concentration fall below the $50 \mathrm{nmol} / \mathrm{L}$ insufficiency threshold

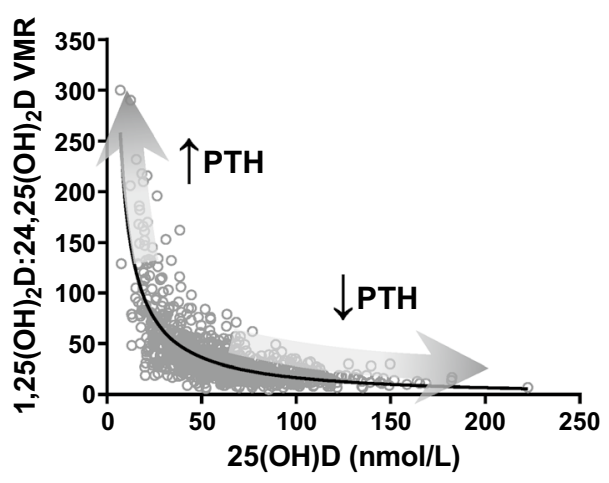

Fig. 1 Distribution of PTH under the influence of $1,25(\mathrm{OH})_{2} \mathrm{D}: 24,25(\mathrm{OH})_{2} \mathrm{D}$ VMR and 25(OH)D. $1,25(\mathrm{OH})_{2} \mathrm{D}: 24,25(\mathrm{OH})_{2} \mathrm{D}$ VMR increases exponentially with the decline of serum $25(\mathrm{OH}) \mathrm{D}$, represented by LOWESS fitted curve (solid line). An increase in PTH concentration accompanies the change 
(Fig. 1) [78]. The evidence suggests as the availability of $25(\mathrm{OH}) \mathrm{D}$ precursors diminishes, the catabolism of $25(\mathrm{OH}) \mathrm{D}$ to $24,25(\mathrm{OH})_{2} \mathrm{D}$ is reduced to allow a proportional increase in serum $1,25(\mathrm{OH})_{2} \mathrm{D}$. The finding was supported by a significant decrease in the distribution PTH concentration observed in individuals with high-low $1,25(\mathrm{OH})_{2} \mathrm{D}: 24,25(\mathrm{OH})_{2} \mathrm{D}$ VMR over low-high 25(OH)D. Understanding the mechanisms controlling the active and catabolic forms of vitamin D metabolites and the interactions with tissue VDR will be the key to unlock the role that vitamin D plays in systemic processes behind calcium homeostasis, bone physiology, muscle function, fracture healing and immune response to inflammation and infection.

\section{Measurement of Vitamin D Metabolites in Tissues and Bodily Fluids Other than Plasma}

Vitamin D, its metabolites and VDBP have been detected and measured in a wide range of human tissues and bodily fluids, other than plasma. These include breast milk, urine, semen, saliva, cerebrospinal and synovial fluid, skin and muscle biopsies and hair samples [89-94]. The collection of such samples may provide benefits, such as ease of sample collection and avoidance of invasive sampling methods or for the investigation of organ-specific aspects of vitamin D metabolism and function. Each of these matrixes may require specific pre-analytical extraction protocols. In some of these sample types, the low concentrations of the analytes of interest may require enrichment to achieve concentrations within measurement ranges. Results derived from both immunoassays and increasingly, chromatographic techniques have been reported. So far, standardisation and quality assurance schemes for assays conducted in matrices other than plasma or serum are lacking. Also, studies investigating potential interferences in assays conducted in these matrices are scarce. With the exception of the recognised low concentrations of vitamin $\mathrm{D}$ and 25(OH)D in human breast milk [94, 95], which has informed clinical and population guidance of vitamin D intake requirements in infancy (The Scientific Advisory Committee on Nutrition [96]), the utility of the measurement of vitamin D metabolites and VDBP is so far limited to research settings. This research has focussed on the presence and availability of vitamin D metabolites and VDBP in order to elucidate the role of vitamin D metabolites within specific organ systems, e.g. in the investigation of para- and autocrine effects and production and catabolism of metabolites. Also, research has aimed to provide mechanistic insights in the role or consequences of abnormalities in vitamin D status or metabolism in pathological conditions. Discussion of this research and the specific analytical challenges associated with this research is beyond the scope of this literature review.

\section{Conclusion}

Major developments have taken place in the measurement of vitamin D metabolites. Advances have been made in the measurement of 25 hydroxyvitamin $\mathrm{D}$, the marker of vitamin D status and of other metabolites that may inform clinical and research practice. The choice of the most appropriate methodology depends on its application, required specificity and accuracy of measurement and technical and financial considerations.

Author Contributions WDF is responsible for the overall content as the guarantor of the paper. All authors have contributed to the drafting and revision of the manuscript.

\section{Compliance with Ethical Standards}

Conflict of interest William D. Fraser, Jonathan C. Y. Tang, John J. Dutton and Inez Schoenmakers declare no conflict of interest.

Open Access This article is distributed under the terms of the Creative Commons Attribution 4.0 International License (http://creativeco mmons.org/licenses/by/4.0/), which permits unrestricted use, distribution, and reproduction in any medium, provided you give appropriate credit to the original author(s) and the source, provide a link to the Creative Commons license, and indicate if changes were made.

\section{References}

1. Fraser WD, Milan AM (2013) Vitamin D assays: past and present debates, difficulties, and developments. Calcif Tissue Int 92(2):118-127

2. Giustina A, Adler RA, Binkley N, Bouillon R, Ebeling PR, Lazaretti-Castro M, Marcocci C, Rizzoli R, Sempos CT, Bilezikian JP (2019) Controversies in Vitamin D: summary statement from an International Conference. J Clin Endocrinol Metab 104(2):234-240

3. Hutchinson K, Healy M, Crowley V, Louw M, Rochev Y (2017) Verification of Abbott 25-OH-vitamin D assay on the architect system. Pract Lab Med 7:27-35

4. Annema W, Nowak A, von Eckardstein A, Saleh L (2018) Evaluation of the new restandardized Abbott Architect 25-OH Vitamin $\mathrm{D}$ assay in vitamin D-insufficient and vitamin D-supplemented individuals. J Clin Lab Anal 32(4):e22328

5. Carter GD, Jones JC, Shannon J, Williams EL, Jones G, Kaufmann M, Sempos C (2016) 25-Hydroxyvitamin D assays: potential interference from other circulating vitamin D metabolites. J Steroid Biochem Mol Biol 164:134-138

6. Freeman J, Wilson K, Spears R, Shalhoub V, Sibley P (2015) Performance evaluation of four 25-hydroxyvitamin $\mathrm{D}$ assays to measure 25-hydroxyvitamin D2. Clin Biochem 48(16-17):1097-1104

7. Wyness SP, Straseski JA (2015) Performance characteristics of six automated 25-hydroxyvitamin D assays: mind your $3 \mathrm{~s}$ and 2s. Clin Biochem 48(16-17):1089-1096

8. Dowling KG, Hull G, Sundvall J, Lamberg-Allardt C, Cashman KD (2017) Improved accuracy of an tandem liquid chromatography-mass spectrometry method measuring 24R,25-dihydroxyvitamin D3 and 25-hydroxyvitamin D metabolites in serum 
using unspiked controls and its application to determining crossreactivity of a chemiluminescent microparticle immunoassay. $\mathbf{J}$ Chromatogr A 1497:102-109

9. Karvaly G, Meszaros K, Kovacs K, Patocs A, Sipak Z, Vasarhelyi B (2017) Looking beyond linear regression and Bland-Altman plots: a comparison of the clinical performance of 25-hydroxyvitamin D tests. Clin Chem Lab Med 55(3):385-393

10. Hara K, Ikeda K, Koyama Y, Wada Y, Hasegawa T (2018) Comparison of serum 25-hydroxyvitamin $\mathrm{D}$ levels between radioimmunoassay and liquid chromatography-tandem mass spectrometry in infants and postpartum women. J Pediatr Endocrinol Metab 31(10):1105-1111

11. Valcour A, Zierold C, Podgorski AL, Olson GT, Wall JV, DeLuca HF, Bonelli F (2016) A novel, fully-automated, chemiluminescent assay for the detection of 1,25-dihydroxyvitamin D in biological samples. J Steroid Biochem Mol Biol 164:120-126

12. Tran, J, Bautista, D, Seres, Z, Cornaut, L, Gundlach, T, Rousseau, A, and Griesser, H. 1,25-Dihydroxy vitamin D assay with on-board sample purification on the IDS-iSYS automated system. Bone Abstracts 2014; 3: PP81. Presented at European Calcified Tissue Society Congress. Czech Republic, Prague Poster

13. Denimal D, Lemaire-Ewing S, Duvillard L (2015) Performance of a new 1,25-dihydroxyvitamin D fully automated assay on IDSiSYS system. Clin Biochem 48(16-17):1209-1210

14. Spanaus K, von Eckardstein A (2017) Evaluation of two fully automated immunoassay based tests for the measurement of 1alpha,25-dihydroxyvitamin $\mathrm{D}$ in human serum and comparison with LC-MS/MS. Clin Chem Lab Med 55(9):1305-1314

15. Souberbielle JC, Cavalier E, Delanaye P, Massart C, BraillyTabard S, Cormier C, Borderie D, Benachi A, Chanson P (2015) Serum calcitriol concentrations measured with a new direct automated assay in a large population of adult healthy subjects and in various clinical situations. Clin Chim Acta 451(Pt B):149-153

16. Carpenter TO, Herreros F, Zhang JH, Ellis BK, Simpson C, Torrealba-Fox E, Kim GJ, Savoye M, Held NA, Cole DE (2012) Demographic, dietary, and biochemical determinants of vitamin D status in inner-city children. Am J Clin Nutr 95(1):137-146

17. Higgins V, Truong D, White-Al Habeeb NMA, Fung AWS, Hoffman B, Adeli K (2018) Pediatric reference intervals for 1,25-dihydroxyvitamin D using the DiaSorin LIAISON XL assay in the healthy CALIPER cohort. Clin Chem Lab Med 56(6):964-972

18. Breen, N, Wardle, R, Davey, L, Lambert, P, Roche, D, Crushell, M, and Calton, L (2017) Performance characteristics of the MassTrak vitamin D solution. Waters Corporation, Wilmslow, UK. https://www.waters.com/webassets/cms/library/docs/72000 5942en.pdf. Accessed 7 July 2019

19. SCIEX Vitamin D $200 \mathrm{M}$ Assay for the Topaz ${ }^{\mathrm{TM}}$ System. SCIEX, Framingham, MA, USA 2018. https://sciex.com/Documents/broch ures/clinical/Vitamin_D_Assay_Flyer.pdf. Accessed 7 July 2019

20. Cascadion ${ }^{\mathrm{TM}}$ SM 25-Hydroxy Vitamin D Assay [Ref 10018764] (2019). Thermo Fisher Scientific, Vantaa, Finland. https://www.elabeling.eu/TSF10018764IFU/60547/EN\#remarkPopup. Accessed 7 July 2019

21. Bruce SJ, Rochat B, Beguin A, Pesse B, Guessous I, Boulat O, Henry H (2013) Analysis and quantification of vitamin D metabolites in serum by ultra-performance liquid chromatography coupled to tandem mass spectrometry and high-resolution mass spectrometry-a method comparison and validation. Rapid Commun Mass Spectrom 27(1):200-206

22. Binkley N, Sempos CT, Vitamin DSP (2014) Standardizing vitamin D assays: the way forward. J Bone Miner Res 29(8):1709-1714

23. Wise SA, Phinney KW, Tai SS, Camara JE, Myers GL, DurazoArvizu R, Tian L, Hoofnagle AN, Bachmann LM, Young IS et al (2017) Baseline assessment of 25-hydroxyvitamin D assay performance: a vitamin D standardization program (VDSP) interlaboratory comparison study. J AOAC Int 100(5):1244-1252

24. Phinney KW, Tai SS, Bedner M, Camara JE, Chia RRC, Sander LC, Sharpless KE, Wise SA, Yen JH, Schleicher RL et al (2017) Development of an improved standard reference material for vitamin D metabolites in human serum. Anal Chem 89(9):4907-4913

25. Tai S, Nelson M, Bedner M, Lang B, Phinney K, Sander L, Yen J, Betz J, Sempos C, Wise S (2017) Development of standard reference material (SRM) 2973 vitamin D metabolites in frozen human serum (high level). J AOAC Int 100(5):1294-1303

26. Durazo-Arvizu RA, Ahmed F, Berry J, Cavalier E, Gunter E, Jones G, Jones J, Sempos CT, Twomey PJ, Williams EL et al (2019) Estimating uncertainty of target values for DEQAS serum materials. J Steroid Biochem Mol Biol 188:90-94

27. Cashman KD, Dowling KG, Skrabakova Z, Gonzalez-Gross M, Valtuena J, De Henauw S, Moreno L, Damsgaard CT, Michaelsen KF, Molgaard C et al (2016) Vitamin D deficiency in Europe: pandemic? Am J Clin Nutr 103(4):1033-1044

28. Bhan I, Powe CE, Berg AH, Ankers E, Wenger JB, Karumanchi SA, Thadhani RI (2012) Bioavailable vitamin D is more tightly linked to mineral metabolism than total vitamin $\mathrm{D}$ in incident hemodialysis patients. Kidney Int 82(1):84-89

29. Nielson CM, Jones KS, Bouillon R, Osteoporotic Fractures in Men Research G, Chun RF, Jacobs J, Wang Y, Hewison M, Adams JS, Swanson CM et al (2016) Role of assay type in determining free 25-hydroxyvitamin D levels in diverse populations. N Engl J Med 374(17):1695-1696

30. Nielson CM, Jones KS, Chun RF, Jacobs JM, Wang Y, Hewison M, Adams JS, Swanson CM, Lee CG, Vanderschueren D et al (2016) Free 25-Hydroxyvitamin D: impact of vitamin D binding protein assays on racial-genotypic associations. J Clin Endocrinol Metab 101(5):2226-2234

31. Schwartz JB, Gallagher JC, Jorde R, Berg V, Walsh J, Eastell R, Evans AL, Bowles S, Naylor KE, Jones KS et al (2018) Determination of free $25(\mathrm{OH}) \mathrm{D}$ concentrations and their relationships to total 25(OH)D in multiple clinical populations. J Clin Endocrinol Metab 103(9):3278-3288

32. Bikle DD, Gee E, Halloran B, Kowalski MA, Ryzen E, Haddad JG (1986) Assessment of the free fraction of 25-hydroxyvitamin D in serum and its regulation by albumin and the vitamin D-binding protein. J Clin Endocrinol Metab 63(4):954-959

33. Pettifor JM, Bikle DD, Cavaleros M, Zachen D, Kamdar MC, Ross FP (1995) Serum levels of free 1,25-dihydroxyvitamin D in vitamin D toxicity. Ann Intern Med 122(7):511-513

34. Jemielita TO, Leonard MB, Baker J, Sayed S, Zemel BS, Shults J, Herskovitz R, Denburg MR (2016) Association of 25-hydroxyvitamin $\mathrm{D}$ with areal and volumetric measures of bone mineral density and parathyroid hormone: impact of vitamin D-binding protein and its assays. Osteoporos Int 27(2):617-626

35. Alzaman NS, Dawson-Hughes B, Nelson J, D’Alessio D, Pittas AG (2016) Vitamin D status of black and white Americans and changes in vitamin D metabolites after varied doses of vitamin $\mathrm{D}$ supplementation. Am J Clin Nutr 104(1):205-214

36. Bikle D, Bouillon R, Thadhani R, Schoenmakers I (2017) Vitamin D metabolites in captivity? Should we measure free or total 25(OH)D to assess vitamin D status? J Steroid Biochem Mol Biol 173:105-116

37. Henderson CM, Lutsey PL, Misialek JR, Laha TJ, Selvin E, Eckfeldt JH, Hoofnagle AN (2016) Measurement by a novel LC-MS/MS methodology reveals similar serum concentrations of vitamin D-binding protein in Blacks and Whites. Clin Chem 62(1):179-187

38. Schwartz JB, Lai J, Lizaola B, Kane L, Markova S, Weyland P, Terrault NA, Stotland N, Bikle D (2014) A comparison of measured and calculated free $25(\mathrm{OH})$ vitamin D levels in clinical populations. J Clin Endocrinol Metab 99(5):1631-1637 
39. Heureux N, Lindhout E, Swinkels L (2017) A direct assay for measuring free 25-hydroxyvitamin D. J AOAC Int 100(5):1318-1322

40. Powe CE, Evans MK, Wenger J, Zonderman AB, Berg AH, Nalls M, Tamez H, Zhang D, Bhan I, Karumanchi SA et al (2013) Vitamin D-binding protein and vitamin D status of black Americans and white Americans. N Engl J Med 369(21):1991-2000

41. Aloia J, Dhaliwal R, Mikhail M, Shieh A, Stolberg A, Ragolia L, Fazzari M, Abrams SA (2015) Free 25(OH)D and calcium absorption, PTH, and markers of bone turnover. J Clin Endocrinol Metab 100(11):4140-4145

42. Chun RF, Peercy BE, Orwoll ES, Nielson CM, Adams JS, Hewison M (2014) Vitamin D and DBP: the free hormone hypothesis revisited. J Steroid Biochem Mol Biol 144:132-137

43. Holmlund-Suila E, Pekkinen M, Ivaska KK, Andersson S, Makitie O, Viljakainen H (2016) Obese young adults exhibit lower total and lower free serum 25-hydroxycholecalciferol in a randomized vitamin D intervention. Clin Endocrinol (Oxf) 85(3):378-385

44. Chun RF, Peercy BE, Adams JS, Hewison M (2012) Vitamin D binding protein and monocyte response to 25 -hydroxyvitamin $\mathrm{D}$ and 1,25-dihydroxyvitamin D: analysis by mathematical modeling. PLoS ONE 7(1):e30773

45. Schoenmakers I, Jones KS (2018) Chapter 37: Pharmacology and Pharmacokinetics. In: Feldman D, Pike JW, Bouillon R, Giovannucci E, Goltzman D, Hewison M (eds) Vitamin D volume 1: biochemistry, physiology and diagnostics. Elsevier, Saint Louis, pp 635-653

46. Denburg MR, Hoofnagle AN, Sayed S, Gupta J, de Boer IH, Appel LJ, Durazo-Arvizu R, Whitehead K, Feldman HI, Leonard MB et al (2016) Comparison of two ELISA methods and mass spectrometry for measurement of vitamin D-binding protein: implications for the assessment of bioavailable vitamin D concentrations across genotypes. J Bone Miner Res 31(6):1128-1136

47. Haddad JG Jr, Min C, Mendelsohn M, Slatopolsky E, Hahn TJ (1977) Competitive protein-binding radioassay of 24,25-dihydroxyvitamin D in sera from normal and anephric subjects. Arch Biochem Biophys 182(2):390-395

48. Horst RL, Shepard RM, Jorgensen NA, DeLuca HF (1979) The determination of 24,25-dihydroxyvitamin $\mathrm{D}$ and 25,26-dihydroxyvitamin $\mathrm{D}$ in plasma from normal and nephrectomized man. J Lab Clin Med 93(2):277-285

49. Ornoy A, Goodwin D, Noff D, Edelstein S (1978) 24, 25-dihydroxyvitamin $\mathrm{D}$ is a metabolite of vitamin D essential for bone formation. Nature 276(5687):517-519

50. Shimizu M, Gao Y, Aso T, Nakatsu K, Yamada S (1992) Fluorometric assay of 25-hydroxyvitamin D3 and 24R,25-dihydroxyvitamin D3 in plasma. Anal Biochem 204(2):258-264

51. Sebert JL, Fournier A, Lambrey G, Moriniere P, Decourcelle PH, Makdassi R, De Fremont JF (1982) Does 24,25 dihydroxycholecalciferol have a physiological and pathophysiological role? Nephrologie 3(3):133-141

52. Castro-Errecaborde N, de la Piedra C, Rapado A, Alvarez-Arroyo MV, Torres R, Traba ML (1991) Correlation between serum osteocalcin and 24,25-dihydroxyvitamin D levels in Paget's disease of bone. J Clin Endocrinol Metab 72(2):462-466

53. Schwartz Z, Soskolne WA, Atkin I, Goldstein M, Ornoy A (1989) A direct effect of $24,25-(\mathrm{OH}) 2 \mathrm{D} 3$ and $1,25-(\mathrm{OH}) 2 \mathrm{D} 3$ on the modeling of fetal mice long bones in vitro. J Bone Miner Res 4(2): $157-163$

54. St-Arnaud R, Glorieux FH (1998) 24,25-Dihydroxyvitamin D-active metabolite or inactive catabolite? Endocrinology 139(8):3371-3374

55. Wang TJ, Zhang F, Richards JB, Kestenbaum B, van Meurs JB, Berry D, Kiel DP, Streeten EA, Ohlsson C, Koller DL et al (2010) Common genetic determinants of vitamin D insufficiency: a genome-wide association study. Lancet 376(9736):180-188
56. Streeten EA, Zarbalian K, Damcott CM (2011) CYP24A1 mutations in idiopathic infantile hypercalcemia. N Engl J Med 365(18):1741-1742

57. Jacobs TP, Kaufman M, Jones G, Kumar R, Schlingmann KP, Shapses S, Bilezikian JP (2014) A lifetime of hypercalcemia and hypercalciuria, finally explained. J Clin Endocrinol Metab 99(3):708-712

58. Bosworth CR, Levin G, Robinson-Cohen C, Hoofnagle AN, Ruzinski J, Young B, Schwartz SM, Himmelfarb J, Kestenbaum B, de Boer IH (2012) The serum 24,25-dihydroxyvitamin D concentration, a marker of vitamin D catabolism, is reduced in chronic kidney disease. Kidney Int 82(6):693-700

59. Higashi T, Shimada K (2017) Application of Cookson-type reagents for biomedical HPLC and LC/MS analyses: a brief overview. Biomed Chromatogr 31(1):e3808

60. Jenkinson C, Taylor AE, Hassan-Smith ZK, Adams JS, Stewart PM, Hewison M, Keevil BG (2016) High throughput LC-MS/ MS method for the simultaneous analysis of multiple vitamin D analytes in serum. J Chromatogr B 1014:56-63

61. Kaufmann M, Morse N, Molloy BJ, Cooper DP, Schlingmann KP, Molin A, Kottler ML, Gallagher JC, Armas L, Jones G (2017) Improved screening test for idiopathic infantile hypercalcemia confirms residual levels of serum 24,25-(OH)2 D3 in affected patients. J Bone Miner Res 32(7):1589-1596

62. Ogawa S, Ooki S, Morohashi M, Yamagata K, Higashi T (2013) A novel Cookson-type reagent for enhancing sensitivity and specificity in assessment of infant vitamin D status using liquid chromatography/tandem mass spectrometry. Rapid Commun Mass Spectrom 27(21):2453-2460

63. Muller MJ, Stokes CS, Lammert F, Volmer DA (2016) Chemotyping the distribution of vitamin D metabolites in human serum. Sci Rep 6:21080

64. Wan D, Yang J, Barnych B, Hwang SH, Lee KS, Cui Y, Niu J, Watsky MA, Hammock BD (2017) A new sensitive LC/MS/MS analysis of vitamin D metabolites using a click derivatization reagent, 2-nitrosopyridine. J Lipid Res 58(4):798-808

65. Tang JCY, Nicholls H, Piec I, Washbourne CJ, Dutton JJ, Jackson S, Greeves J, Fraser WD (2017) Reference intervals for serum 24,25-dihydroxyvitamin D and the ratio with 25-hydroxyvitamin D established using a newly developed LC-MS/MS method. J Nutr Biochem 46:21-29

66. Ketha H, Kumar R, Singh RJ (2016) LC-MS/MS for identifying patients with CYP24A1 mutations. Clin Chem 62(1):236-242

67. Molin A, Baudoin R, Kaufmann M, Souberbielle JC, Ryckewaert A, Vantyghem MC, Eckart P, Bacchetta J, Deschenes G, KeslerRoussey G et al (2015) CYP24A1 mutations in a cohort of hypercalcemic patients: evidence for a recessive trait. J Clin Endocrinol Metab 100(10):E1343-E1352

68. de Boer IH, Sachs MC, Chonchol M, Himmelfarb J, Hoofnagle AN, Ix JH, Kremsdorf RA, Lin YS, Mehrotra R, Robinson-Cohen $\mathrm{C}$ et al (2014) Estimated GFR and circulating 24,25-dihydroxyvitamin D3 concentration: a participant-level analysis of 5 cohort studies and clinical trials. Am J Kidney Dis 64(2):187-197

69. Kaufmann M, Gallagher JC, Peacock M, Schlingmann KP, Konrad M, DeLuca HF, Sigueiro R, Lopez B, Mourino A, Maestro $M$ et al (2014) Clinical utility of simultaneous quantitation of 25-hydroxyvitamin D and 24,25-dihydroxyvitamin D by LC-MS/ MS involving derivatization with DMEQ-TAD. J Clin Endocrinol Metab 99(7):2567-2574

70. Cashman KD, Hayes A, Galvin K, Merkel J, Jones G, Kaufmann M, Hoofnagle AN, Carter GD, Durazo-Arvizu RA, Sempos CT (2015) Significance of serum 24,25-dihydroxyvitamin D in the assessment of vitamin D status: a double-edged sword? Clin Chem 61(4):636-645

71. Macdonald HM, Gryka A, Tang JCY, Aucott LS, Fraser WD, Wood AD (2017) Longevity of daily oral vitamin D3 
supplementation: differences in $25 \mathrm{OHD}$ and $24,25(\mathrm{OH}) 2 \mathrm{D}$ observed 2 years after cessation of a 1-year randomised controlled trial (VICtORy RECALL). Osteoporos Int 28(12):3361-3372

72. Boyan BD, Hyzy SL, Pan Q, Scott KM, Coutts RD, Healey R, Schwartz Z (2016) 24R,25-Dihydroxyvitamin D3 protects against articular cartilage damage following anterior cruciate ligament transection in male rats. PLoS ONE 11(8):e0161782

73. Gal-Moscovici A, Gal M, Popovtzer MM (2005) Treatment of osteoporotic ovariectomized rats with $24,25(\mathrm{OH}) 2 \mathrm{D} 3$. Eur J Clin Invest 35(6):375-379

74. St-Arnaud R (2010) CYP24A1-deficient mice as a tool to uncover a biological activity for vitamin D metabolites hydroxylated at position 24. J Steroid Biochem Mol Biol 121(1-2):254-256

75. Martineau C, Naja RP, Husseini A, Hamade B, Kaufmann M, Akhouayri O, Arabian A, Jones G, St-Arnaud R (2018) Optimal bone fracture repair requires 24R,25-dihydroxyvitamin D3 and its effector molecule FAM57B2. J Clin Invest 128(8):3546-3557

76. Stubbs JR, Zhang S, Friedman PA, Nolin TD (2014) Decreased conversion of 25-hydroxyvitamin D3 to 24,25-dihydroxyvitamin D3 following cholecalciferol therapy in patients with CKD. Clin J Am Soc Nephrol 9(11):1965-1973

77. Edouard T, Husseini A, Glorieux FH, Rauch F (2012) Serum 24,25-dihydroxyvitamin D concentrations in osteogenesis imperfecta: relationship to bone parameters. J Clin Endocrinol Metab 97(4):1243-1249

78. Tang JCY, Jackson S, Walsh NP, Greeves J, Fraser WD, Bioanalytical Facility t (2019) The dynamic relationships between the active and catabolic vitamin D metabolites, their ratios, and associations with PTH. Sci Rep 9(1):6974

79. Sanders KM, Stuart AL, Williamson EJ, Simpson JA, Kotowicz MA, Young D, Nicholson GC (2010) Annual high-dose oral vitamin $\mathrm{D}$ and falls and fractures in older women: a randomized controlled trial. JAMA 303(18):1815-1822

80. Bischoff-Ferrari HA, Dawson-Hughes B, Orav EJ, Staehelin HB, Meyer OW, Theiler R, Dick W, Willett WC, Egli A (2016) Monthly high-dose vitamin D treatment for the prevention of functional decline: a randomized clinical trial. JAMA Intern Med 176(2):175-183

81. Carter GD, Ahmed F, Berry J, Cavalier E, Durazo-Arvizu R, Gunter E, Jones G, Jones J, Phinney K, Sempos CT et al (2019) External quality assessment of 24,25-dihydroxyvitamin D3 $(24,25(\mathrm{OH}) 2 \mathrm{D} 3)$ assays. J Steroid Biochem Mol Biol 187:130-133

82. Wise SA, Tai SS, Nelson MA, Burdette CQ, Camara JE, Hoofnagle AN, Laha TJ, Carter GD, Jones J, Williams EL et al (2017) Interlaboratory comparison for the determination of 24,25-dihydroxyvitamin $\mathrm{D}(3)$ in human serum using liquid chromatography with tandem mass spectrometry. J AOAC Int 100(5):1308-1317

83. Yuan C, Kosewick J, He X, Kozak M, Wang S (2011) Sensitive measurement of serum 1alpha,25-dihydroxyvitamin $\mathrm{D}$ by liquid chromatography/tandem mass spectrometry after removing interference with immunoaffinity extraction. Rapid Commun Mass Spectrom 25(9):1241-1249

84. Zittermann A, Ernst JB, Becker T, Dreier J, Knabbe C, Gummert JF, Kuhn J (2016) Measurement of circulating 1,25-dihydroxyvitamin $\mathrm{D}$ : comparison of an automated method with a liquid chromatography tandem mass spectrometry method. Int J Anal Chem 2016:8501435

85. Abu Kassim NS, Shaw PN, Hewavitharana AK (2018) Simultaneous determination of 12 vitamin D compounds in human serum using online sample preparation and liquid chromatography-tandem mass spectrometry. J Chromatogr A 1533:57-65

86. Casetta B, Jans I, Billen J, Vanderschueren D, Bouillon R (2010) Development of a method for the quantification of 1alpha,25(OH)2-vitamin D3 in serum by liquid chromatography tandem mass spectrometry without derivatization. Eur J Mass Spectrom (Chichester) 16(1):81-89

87. Ishige T, Satoh M, Ogawa S, Nishimura M, Matsushita K, Higashi T, Nomura F (2017) Improved sensitivity of serum/plasma 1alpha,25-dihydroxyvitamin D quantification by DAPTAD derivatization. Clin Chim Acta 473:173-179

88. Ivison FM, Hinchliffe E, Howarth N, Pickersgill M, Tetlow L (2019) Development of a mass spectrometry method for 1,25-dihydroxy vitamin D3 using immunoextraction sample preparation. Ann Clin Biochem. https://doi.org/10.1177/00045 63219847225

89. Li D, Jeffery LE, Jenkinson C, Harrison SR, Chun RF, Adams JS, Raza K, Hewison M (2019) Serum and synovial fluid vitamin D metabolites and rheumatoid arthritis. J Steroid Biochem Mol Biol $187: 1-8$

90. Tamblyn JA, Jenkinson C, Larner DP, Hewison M, Kilby MD (2018) Serum and urine vitamin D metabolite analysis in early preeclampsia. Endocr Connect 7(1):199-210

91. Kulakowska A, Tarasiuk J, Kapica-Topczewska K, Chorazy M, Pogorzelski R, Kulczynska-Przybik A, Mroczko B, Bucki R (2018) Pathophysiological implications of actin-free Gc-globulin concentration changes in blood plasma and cerebrospinal fluid collected from patients with Alzheimer's disease and other neurological disorders. Adv Clin Exp Med 27(8):1075-1080

92. Bishnoi RJ, Palmer RF, Royall DR (2015) Vitamin D binding protein as a serum biomarker of Alzheimer's disease. J Alzheimers Dis 43(1):37-45

93. Lee DH, Kang H, Kim JH, Jung MH, Cho MC (2019) Cerebrospinal fluid vitamin D-binding protein as a new biomarker for the diagnosis of meningitis. Neurol Sci 40(8):1597-1605

94. Vieth Streym S, Hojskov CS, Moller UK, Heickendorff L, Vestergaard P, Mosekilde L, Rejnmark L (2016) Vitamin D content in human breast milk: a 9-mo follow-up study. Am J Clin Nutr 103(1):107-114

95. Wall CR, Stewart AW, Camargo CA Jr, Scragg R, Mitchell EA, Ekeroma A, Crane J, Milne T, Rowden J, Horst R et al (2016) Vitamin D activity of breast milk in women randomly assigned to vitamin D3 supplementation during pregnancy. Am J Clin Nutr 103(2):382-388

96. SACN, Vitamin D and Health report. Scientific Advisory Committee on Nutrition (2016) Public Health England. TSO, London

Publisher's Note Springer Nature remains neutral with regard to jurisdictional claims in published maps and institutional affiliations. 